\title{
Recorridos por las memorias de Ensenada. El caso del Espacio de Cultura y Memoria El Rancho Urutaú y sus representaciones de los desaparecidos y asesinados por el terrorismo de Estado de los setenta. Tesis de Maestría en Historia y Memoria
}

\author{
Melina Jean Jean \\ Instituto de Investigaciones en Humanidades y Ciencias Sociales, \\ Universidad Nacional de La Plata/CONICET, Argentina \\ melinajeanjean@gmail.com
}

Defensa de tesis: 28 de marzo de 2018

Directora: Patricia Flier (UNLP)

Codirectora: Marcela Andruchow (UNLP)

\section{ReSUMEN:}

La obra artística del Espacio de Cultura y Memoria el Rancho Urutaú se inscribe en los diversos modos en que el pasado de la espiral de violencia y el terrorismo de Estado de los años setenta del siglo XX en Argentina y sus consecuencias ha sido abordado. A lo largo de esta investigación, presentamos y analizamos las particularidades del caso que devienen de los hechos en su escala local: el trabajo de las memorias en la ciudad de Ensenada, provincia de Buenos Aires. El objetivo general es conocer el proyecto "Mosaicos por la memoria" del grupo Rancho Urutaú (2010-2017) apuntando a los modos de representación de desaparecidos/as y asesinados ensenadenses. El proyecto se materializa a través de murales con técnica de mosaico, emplazados en los barrios a los que pertenecían los/as homenajeados/as. Estos murales, a escala urbana, privilegian representaciones figurativas que a partir de una narrativa humanitaria recuperan un perfil identitario que apela a aquello cotidiano, lúdico, y ameno de la vida de esas personas. Nuestra hipótesis central es que los murales emplazados adquieren la cualidad de lugares de memoria tanto para los integrantes del grupo como para los familiares y allegados de los homenajeados. En este sentido, la pregunta que guía esta investigación es ¿Cómo un espacio puede convertirse en un lugar de memoria? O bien ¿Qué significa y qué implica que un espacio se convierta en un lugar de memoria?

Palabras Clave: Desaparecidos/as-asesinados, Ensenada, Rancho Urutaú, Lugares de memoria.

La experiencia del terrorismo de Estado de los setenta en Argentina expresó un proceso que tuvo como resultado profundas transformaciones sociales. El terrorismo de Estado ejerció censuras, condenas, desapariciones, asesinatos y una larga lista de violaciones a los derechos humanos. Apuntó a sectores profesionales, intelectuales, educativos, religiosos, artísticos, a movimientos vecinales, grupos culturales, y diversas entidades civiles. Sin embargo, fue la clase trabajadora, en especial los obreros, delegados de fábrica, dirigentes sindicales de base, estudiantiles y barriales quienes engrosaron el porcentaje mayoritario de personas desaparecidas y asesinadas. Según el informe de la CONADEP, los porcentajes de víctimas de la represión que continúan desaparecidas o que fueron liberadas después de pasar por centros clandestinos de detención son: obreros $30,2 \%$, estudiantes $21 \%$, empleados $17,9 \%$, profesionales $10,7 \%$, docentes $5,7 \%$, autónomos y varios 5\% (2016, p. 296).En este sentido, la ciudad de Ensenada -caracterizándose desde sus orígenes como una ciudad de trabajadores y cuyo sustento económico principal se halla desde entonces en su desarrollo industrial y comercial- se vio particularmente afectada. Las luchas obrero-estudiantiles y la fuerte concentración de fuerza policial y militar contribuyeron a que la región de la provincia de Buenos Aires 
conformada por Ensenada, Berisso y La Plata fuese una de las más golpeadas por el terrorismo de Estado en el país (da Silva Catela, 2009).

Sin embargo, este terrorismo de Estado que basó su metodología sistemática e ilegal en los campos de concentración y el asesinato y desaparición forzada de personas, movilizó muy tempranamente la resistencia de grupos sociales y organizaciones defensoras de los derechos humanos. Desde los últimos años de la dictadura y durante las tres décadas siguientes a la restauración democrática de 1983, las principales demandas $\mathrm{y}$ acciones giraron en torno a las denuncias y a la condena de las violaciones a los derechos humanos de aquel período, es decir en la búsqueda de verdad y justicia. A estos reclamos,y en principio en oposición a las políticas de olvido y clausura instaladas desde los propios perpetradores, se sumó la exigencia de memoria. Esto en particular, estableció relaciones con los variados esfuerzos por explicar, comprender y elaborar nuestro pasado reciente. Muchas de estas demandas y reclamos se tradujeron en prácticas de memoria que a través de diferentes lenguajes, entre ellos los artísticos, emergieron en el espacio público para demandar y disputar los recuerdos, para conmemorar y homenajear a las víctimas. Estas demandas y políticas de "memorialización" (Jelin, 2017) se han traducido en proyectos, programas y planes de emprendimientos como la recuperación de sitios como los centros clandestinos de detención y tortura, la creación de parques, paseos y plazas, museos, archivos y espacios culturales. También en el emplazamiento de monumentos, placas, monolitos, baldosas, murales, nombramiento de calles, plantación de árboles, entre otros. Se trata en definitiva de la resignificación, puesta en valor, o bien de la creación y construcción, de diversos soportes de memorias en espacios públicos urbanos que pueden adquirir el estatus de lugares de memoria (Norá, 1998).

Entonces, nos referimos a la construcción colectiva de marcas de memoria que al menos desde la década de los noventa en Argentina ha sido una constante. Sin embargo, a partir de la asunción de Néstor Kirchner en mayo de 2003 hubo un aumento significativo de las mismas, pues el gobierno asumió como política de Estado la condena de la violación de los derechos humanos realizadas durante la última dictadura y el impulso a una política pública de la Memoria (Flier, 2008). En este sentido, durante los gobiernos kirchneristas, hubo muchas iniciativas y políticas ligadas a la memoria, que según Elizabeth Jelin (2017), respondían a la identificación cada vez más cercana del gobierno con las demandas históricas del movimiento de derechos humanos. La nueva coyuntura particular evidenció iniciativas impulsadas por el Estado y diversos grupos de la sociedad civil, que no sin tensiones y disputas, lograron algunas veces trabajar en conjunto. En la ciudad de Ensenada, también a partir del año 2003, el nuevo gobierno municipal encabezado por el Intendente Mario Secco, se alineó a la conducción nacional, propiciando un escenario en el que desde entonces hemos registrado un aumento significativo de marcas, acciones, y políticas públicas de memoria por parte de diversos agentes sociales.

En este contexto emerge nuestro estudio de caso: el proyecto "Mosaicos por la Memoria" que lleva adelante desde el año 2010 el grupo Espacio de Cultura y Memoria El Rancho Urutaú. Se trata de las representaciones plástico visuales de desaparecidos y asesinados -en su mayoría obreros- de la ciudad de Ensenada que se soportan en murales con técnica de mosaico, emplazados en los barrios a los que pertenecían los/as homenajeados/as. Estos murales, a escala urbana, privilegian representaciones figurativas, que a partir de una narrativa humanitaria recuperan un perfil identitario que apela a aquello cotidiano, lúdico, y ameno de la vida de esas personas. Hasta el momento son cuatro los murales inaugurados:

- Primer Mural "Fortunato “Nato” Andreucci”. Inaugurado el 05/03/11.

- Segundo Mural “Mario Gallego y María del Carmen Toselli”. Inaugurado el 04/06/11.

- Tercer Mural “Carlos Esteban Alaye”. Inaugurado el 15/04/12.

- Cuarto Mural “Carlos Guillermo Díaz y Marta Susana Alaniz”. Inaugurado el 26/04/14

A través del proyecto, el Rancho Urutaú pretende "emerger del silencio en que se ha sumido a la ciudadanía (...) esclareciendo la historia inmediata, para sintetizar la experiencia y que el "Nunca Más" sea un hecho" . Además, busca reconstruir el entramado social que directa o indirectamente fue intervenido durante la última 
dictadura en la ciudad, restableciendo vínculos, regenerando lazos con los familiares, allegados y vecinos de los homenajeados. Este grupo de ciudadanos, trabaja sobre determinadas memorias del pasado reciente de la ciudad, y en este sentido, consideramos que sus integrantes se posicionan como "emprendedores" de esas memorias (Jelin, 2002) en tanto generadores de un proyecto de trabajo organizado a partir de nuevas ideas y expresiones de creatividad. Nuestra hipótesis central es que los murales emplazados en los barrios ensenadenses adquieren la cualidad de lugares de memoria tanto para los integrantes del grupo como para los familiares y allegados de los/as homenajeados/as. En este sentido, la pregunta que guía esta investigación es ¿Cómo un espacio puede convertirse en un lugar de memoria? O bien ¿Qué significa y qué implica que un espacio se convierta en un lugar de memoria?

La investigación fue dividida en dos partes. En cada una desarrollamos los diferentes objetivos específicos. La primera parte contiene el capítulo uno. En este apartado nos dedicamos a describir el desarrollo económico, político y social de la región en diálogo con la historia nacional para focalizar nuestra atención en Ensenada. Además, realizamos un registro, relevamiento y descripción de marcas, acciones y políticas públicas de memoria para poder observar los antecedentes de este tipo de prácticas en la ciudad. El registro fue realizado mediante la toma de fotografías que fueron anexadas al final de dicho capítulo. En su conjunto, esta primera parte pretende dar a conocer el contexto de emergencia de los trabajos de memorias que realiza el Rancho Urutaú en el espacio público de Ensenada. La segunda parte nos introduce específicamente en nuestro estudio de caso. El capítulo dos, presenta al grupo Rancho Urutaú, y recupera, por un lado, sus inicios, los modos de aglutinamiento, así como las características y trayectorias de sus integrantes. Por otro lado, se presenta el proyecto "Mosaicos por la Memoria", los objetivos y su funcionamiento; el soporte seleccionado para su materialización, es decir, el arte monumental: el muralismo; y finalmente las etapas de construcción de los murales que denominamos: proceso de investigación; proceso plástico y emplazamiento; difusión, inauguración y acto conmemorativo. Este capítulo no cuenta con un anexo de imágenes aparte, sino que las mismas fueron estratégicamente situadas dentro del texto para facilitar la lectura. En el capítulo tres, abordamos la presentación, descripción y análisis iconográfico y formal de nuestro corpus de obras artísticas: los cuatro murales emplazados e inaugurados hasta el presente. El tratamiento de las imágenes sigue la misma lógica que el capítulo precedente. En el capítulo cuatro, alcanzamos el nivel de significación e interpretación de los murales: analizamos el tipo de representación de los/as desaparecidos/as y asesinados realizada por el Rancho Urutaú. Esto nos llevó previamente, a realizar un repaso general de las narrativas, matrices y modalidades -ampliamente utilizadas y difundidas- de representaciones del horror y las desapariciones en Argentina para focalizarnos en el uso y producción de imágenes plásticas. Es a partir de este capítulo y en el siguiente, donde a las narraciones de los integrantes del grupo, se suman las de los familiares y allegados. Por último, en el capítulo cinco nos dedicamos a poder demostrar que estos murales se han convertido en lugares de memoria. Lugares de memoria que trasmiten los intensos y complejos trabajos por conocer, reconocer y reparar simbólicamente las heridas, las ausencias, los silencios que caracterizan a este pasado que no pasa (Rousso, 2018) en Ensenada -también en todo nuestro país- tópicos sobre los que venimos trabajando desde el capítulo dos de esta tesis y que ha sido nuestro desvelo central para explicar los sentidos otorgados a los trabajos de las memorias del grupo Rancho Urutaú.

\section{REFERENCIAS}

Comisión Nacional sobre la Desaparición de Personas (CONADEP)[1984] (2016)Nunca Más. Informe de la Comisión Nacional sobre la Desaparición de Personas. Buenos Aires: EUDEBA.

Da Silva Catela, Ludmila (2009). No habrá flores en la tumba del pasado. La experiencia de reconstrucción del mundo de los familiares de desaparecidos. La Plata, Al Margen. 
Flier, Patricia (2008) “Políticas de la memoria en el pasado reciente de Argentina. 1976-2010”. Presentación en el Seminario Internacional "Memoria y derechos humanos: desafíos para un circuito de Memoria”. Proyecto Rutas de la Memoria INNOVO Chile 09 /USAH, Santiago de Chile.

Jelin, Elizabeth (2002). Los trabajos de la memoria. Madrid. Siglo XXI.

Jelin, Elizabeth (2017). La Lucha por el pasado: Cómo construimos la memoria social. Buenos Aires, Siglo XXI Editores.

Norá, Pierre [1984-1993] (1998). "La aventura de Les lieux de mémoire”, Ayer (32), Madrid, Asociación de Historia Contemporánea. Disponible en: http://www.ahistcon.org/docs/ayer/AYER32_02.pdf

Rousso, Henry (2018) "Desarrollos de la historiografía de la memoria”, Aletheia, 8(16). Disponible en: http://www.a letheia.fahce.unlp.edu.ar/numeros/numero-16/conferencia/Conferencia\%20Henry\%20Rousso.doc.pdf

\section{Notas}

1 Recuperado de: "Rancho Urutaú, Proyecto "Mosaicos por la Memoria" Desaparecidos de Ensenada" 11 de abril de 2011, https://www.facebook.com/notes/el-rancho-urutau/proyecto-mosaicos-por-la-memoria-desaparecidos-deen senada/107189206034151/ 